Revista lus et Praxis, Año 17, № 2, 2011, pp. 53 - 76

ISSN 0717 - 2877

Universidad de Talca - Facultad de Ciencias Jurídicas y Sociales

"La iniciativa probatoria del juez y la igualdad de armas en el proyecto de Código Procesal Civil"

Iván Hunter Ampuero

\title{
LA INICIATIVA PROBATORIA DEL JUEZY LA IGUALDAD DE ARMAS EN EL PROYECTO DE CÓDIGO PROCESAL CIVIL*
}

\author{
THE JUDGE'S PROBATIVE INITIATIVE AND EQUALITY OF WEAPONS IN THE CIVIL \\ PROCEDURAL CODE PROJECT
}

IvÁN Hunter Ampuero**

\section{RESUMEN}

El presente trabajo reúne dos propósitos: el primero, explicar cuál es la relación entre la igualdad procesal y la actividad probatoria del juez, es decir, definir si la iniciativa jurisdiccional ex officio en materia de pruebas puede destinarse a lograr equilibrios procesales cuando los sujetos se presentan en situaciones de desigualdad sustantiva. El segundo es determinar el rol que debe asumir el juez en razón de las exigencias de igualdad que impregnan al proceso, cuya vigencia se le encomienda al juez en el Proyecto de Código Procesal Civil.

ABSTRACT

The present work meets two purposes: First of all, to explain what is the relation between procedural equality and judge's probative activity. Thus, to define if the ex officio jurisdictional initiative related to proofs can lead to achieve procedural balances when individuals are surrounded by substantive inequality. Secondly, to define the role to be assumed by the judge according to the equality requirements which involve a trial. These requirements are entrusted to the judge in the Civil

Procedural Code Project.

PALABRAS CLAVE

Igualdad Procesal, Poderes Probatorios, Imparcialidad del Juez

KEY WORDS

Procedural Equality, Probative Power, Judge's Impartiality

\section{INTRODUCCIÓN}

El Proyecto de Código Procesal Civil (en adelante el PCPC) ha positivizado en normas concretas una serie de principios del proceso y del procedimiento.

\footnotetext{
* Este trabajo fue realizado en el marco y con el financiamiento de la Dirección de Investigación y Desarrollo de la Universidad Austral de Chile (DID), proyecto N²010-12 (2010-2011), titulado "El rol del juez en el Proyecto de Código Procesal Civil", del cual el autor de este trabajo es su investigador responsable. Trabajo recibido el 23 de mayo y aprobado el 28 de junio de 2011.

** Abogado, Doctor en Derecho por la Universidad Carlos III, de Madrid y Magíster en Derecho, Universidad Austral de Chile; Profesor de Derecho Procesal de la Universidad Austral de Chile. Correo electrónico: ivanhunter@uach.cl.
} 
Ese es el caso de la igualdad de armas, consagrado en el Art. $5^{\circ}$, que establece: "El tribunal velará por mantener la igualdad de las partes en el proceso". El tenor de esta disposición y su naturaleza pueden generar algunas dificultades al momento de determinar su alcance. Como es sabido, los principios pueden cumplir diferentes funciones. En algunos casos están llamados a integrar lagunas o vacíos legislativos; en otros, son herramientas hermenéuticas que sirven para discernir correctamente el sentido de una regla jurídica. En fin, para otros, constituyen mandatos de optimización que deben perseguirse en la mayor medida posible.

Con todo, el PCPC otorga una misión al juez: velar por mantener la igualdad en el proceso. Pero ¿qué alcance tiene esa disposición? ¿Puede legitimar esa norma una posición activa del juez en la recopilación del material probatorio? ¿Tiene por finalidad que la actividad probatoria del juez elimine cualquier diferencia sustancial entre los litigantes? Son esas las interrogantes que pueden surgir cuando se trata de definir el papel que debe desempeñar el juez en relación a la igualdad, dudas que se justifican en la medida que este mismo cuerpo normativo permite al juez decretar todas las diligencias necesarias para esclarecer la verdad de los hechos respetando el derecho de defensa (Art. $18 \mathrm{~N}^{\circ} 4$ PCPC). Hay, por tanto, una clara tarea de armonizar esas normas.

En las próximas líneas pretendo responder las interrogantes planteadas asumiendo como hipótesis que la exigencia de igualdad procesal no puede estar destinada a legitimar un rol activo del juez en la recopilación del material probatorio. En simples palabras, la misión del juez de mantener la igualdad no pretende exigirle que utilice su iniciativa probatoria para lograr equilibrios procesales cuando los sujetos se encuentran en una posición asimétrica, habiendo uno débil y uno fuerte.

Para esa finalidad pretendo: (II) dar cuenta de los diversos aspectos donde es reconocible las exigencias igualdad en el derecho procesal civil; (III) describir sumariamente las tendencias comparadas que aceptan un rol asistencial del juez en materia probatoria; (IV) analizar los diferentes ámbitos donde es posible advertir la presencia de desigualdades con incidencia procesal, y determinar cómo actúa el Derecho para equilibrar a los litigantes; (V) por último, pretendo dar a conocer una interpretación del PCPC acerca de la consecución de la igualdad sustantiva a través de la actividad probatoria del juez, y proponer ciertos elementos que deberían estar presentes en esa misma. Se finaliza con las conclusiones $(\mathrm{V})$.

\section{ACERCA DE LA IGUALDAD EN El PROCESO CIVIL}

Creo que no se necesita justificar que el proceso civil para ser considerado auténticamente el ejercicio dinámico de la jurisdicción debe conformarse sobre tres elementos esenciales: la dualidad de posiciones, la contradicción y la igualdad 
de las partes ${ }^{1}$. El principio de igualdad procesal es una proyección en el ámbito infraconstitucional del principio general de igualdad ante la ley, reconocido en la Constitución (Art. 19 № 2 de la Constitución Política de la República), y que forma parte de la cláusula del justo y racional procedimiento ${ }^{2}$.

Es evidente que las exigencias constitucionales de igualdad y de debido proceso condicionan la estructura del proceso y de sus etapas. Así, la distribución de las facultades y deberes procesales entre el que ejerce una pretensión y quien se opone, deben organizarse de tal forma de asegurar (salvo las excepciones y limitaciones constitucionalmente autorizadas) el perfecto o razonable equilibrio. Se trata, en definitiva, de asegurar legislativa y judicialmente la posibilidad para cada uno de los destinatarios del pronunciamiento jurisdiccional de participar en la formación de su contenido, en recíproca y simétrica paridad ${ }^{3}$.

Esta idea general acerca de la igualdad permite separar claramente los aspectos en la que opera. Al respecto, es reconocible un aspecto netamente estático y otro dinámico. El primero es una directriz hacia el legislador, donde la igualdad toma un nombre e identidad propia acuñada en el derecho alemán: la igualdad de armas. Siguiendo a ANDOLINA y ViGNeRA, es posible entender la igualdad de armas como "la obligación del legislador de colocar a las partes del proceso en una posición de paridad, asegurándole un mismo tratamiento normativo y la titularidad de poderes, deberes y facultades simétricamente iguales y mutuamente relacionadas" ${ }^{\prime 4}$. En un sentido más general, se trata de

\footnotetext{
${ }^{1}$ Vid., entre otros: Montero Aroca, Juan, Derecho Jurisdiccional l, Parte General (con Gómez Colomer, Montón Redondo y Barona Vilar), Tirant lo Blanch, Valencia, 2003, pp. 322 y ss.; Ortells Ramos, Manuel, Derecho Procesal, Introducción (con Sánchez y Cámara), Edisofer Libros Jurídicos, Madrid, 2006, p. 261 y siguientes; Rifá Soler, José; Richard Gonzálezz, Manuel; Riaño Brun, Iñaki, Derecho Procesal Civil, Vol. I, Gobierno de Navarra, Pamplona, 2005, p. 45; Asencio Mellado, José, Introducción al Derecho Procesal, Tirant lo Blanch, Valencia, 1997, pp. 201 y 202, y Cortés Domínguez, Valentín, Introducción al Derecho Procesal, Tirant lo Blanch, Valencia, 2003, p. 258.

${ }^{2}$ Como es sabido esta es la fórmula criolla del debido proceso, consagrado en el Art. $19 \mathrm{~N}^{\circ} 3$, inciso 5 de la Constitución.

${ }^{3}$ Vid., Andolina, Italo; Vignera, Giuseppe, I fondamento costituzionali della giustizia civile. Il modello costituzionale del processo civile italiano, Giappicchelli Editore, Torino, 1997, p. 113.

${ }^{4}$ ANDOLINA; VIGNeRA, I fondamento, cit. nota. n. 3, p. 118. Este es el sentido que tradicionalmente suele darse a la igualdad procesal, entendida como igualdad de armas. Vid., también: Cortés Domínguez, Valentín, "La Constitución española y los principios rectores del proceso civil", en Principios constitucionales del proceso civil, Consejo General Poder Judicial, Madrid, 1993, p. 147; MONTERO, Derecho, cit. nota. n. 1, p. 329; Serrano Horo, Gregorio, La prohibición de indefensión y su incidencia en el proceso, Editorial Comares, Granada, 1997, p. 108. Ramos Méndez, Francisco, Derecho y proceso, Bosch Editor, Barcelona, 1979, p. 265, explica que el ejercicio de la acción implica siempre a varios sujetos en su vocación de juicio; de esta constatación nace la necesidad técnica de coordinar las expectativas y cargas procesales en régimen de igualdad. En casi idéntico sentido: Picó I Junor, Joan, Las garantías constitucionales del proceso, Bosch Editor, Barcelona, 1997, p. 132, quien escribe que se trata de que ambas partes gocen de las mismas posibilidades y cargas de alegación, prueba e impugnación.
} 
un "equilibrio en sus derechos de defensa" ${ }^{5}$ sin conceder a ninguna de ellas un trato favorable, salvo casos excepcionales, donde el equilibrio no pueda sino que mantenerse con un trato procesal desigualitario.

Con todo, no se trata de una construcción simétrica de facultades, cargas y deberes de las partes, por cuanto la dinámica procesal, la naturaleza de la disputa o simplemente la estructura o clase de proceso pueden condicionar su distribución. Nadie podría, por ejemplo, asegurar que si un litigante debe asumir la carga de acreditar un hecho, ello suponga romper el principio de igualdad. O si el juez decide invertir la carga de la prueba por la cercanía de un litigante a la fuente de prueba, signifique una ruptura del principio. Se trata, en síntesis, de sostener una "razonable igualdad de posibilidades" ${ }^{6}$, con el objeto que las partes puedan influir en el resultado final del proceso. El proceso debe articularse como una balanza equilibrada de posibilidades de acción y defensa, para uno $u$ otro litigante.

El otro extremo de la igualdad es su aspecto dinámico, donde la directriz va dirigida al juez. Tradicionalmente, esta vertiente consiste "en que, salvo excepciones establecidas en la ley, toda petición o pretensión formulada por una de las partes en el proceso, debe ser comunicada a la parte contraria para que pueda ésta prestar a ella su consentimiento o formular su oposición" ${ }^{\prime \prime}$. Siendo así la igualdad hace referencia a la contradicción. El ciudadano tiene que ser informado de la existencia de los actos procesales realizados o por realizarse, con la finalidad de ejercer el derecho de ser escuchado e impedir ulteriores efectos en su contra. La igualdad permite la participación equitativa de los litigantes en una contraposición de argumentos, con la finalidad de que el juez recoja los elementos formativos de la decisión ${ }^{8}$. De esta forma, el juez asume el importante rol de ser el promotor del contradictorio en todos los extremos de la disputa, y verifica que ambas partes se encuentren -abstractamente- en una posición de igualdad.

\footnotetext{
${ }^{5}$ Morón Palomino, Manuel, Derecho Procesal Civil (Cuestiones fundamentales), Marcial Pons, Madrid, 1993, p. 74.

6 Couture, Eduardo, Fundamentos del derecho procesal civil, tercera edición, ediciones Depalma, Buenos Aires, 1988, p. 185. Incluso, como afirma Ubertazzı, Giovanni, "Divieto di discriminazione e uguaglianza delle armi nel processo civile", Rivista Trimestrale di Diritto e Procedura Civile año XXXI, 1977, p. 562, siguiendo la jurisprudencia de la Comisión de Derechos Humanos, situar en un plano de paridad a dos partes no significa necesariamente reconocer de manera absoluta iguales condiciones.

7 Como lo afirma Couture, Fundamentos, cit. nota. n. 6, p. 183, el principio de igualdad que domina el proceso civil se resume en el brocardo: auditur altera pars (óigase a la otra parte)".

8 Do PASSo, Antonio, "Il principio del contraddittorio come diritto influenza e dovere di dibattito", Rivista di Diritto Processuale LX, № 2, 2005, p. 451, y VerDE, Giovanni, Profili del proceso civile. Parte generale, Jovene Editore, Nápoles, 1988, p. 96.
} 


\section{LA ACTIVIDAD PROBATORIA DEL JUEZ CIVIL Y SU ROL ASISTENCIAL}

A partir de la ZPO austriaca de Franz Klein de 1895, una parte sostenida de la doctrina ha venido afirmando un rol asistencial del juez en el proceso civil. Se dice que los poderes y deberes reconocidos al órgano jurisdiccional deben ser ejercidos a favor de la parte más débil o peor defendida, con la finalidad de lograr una efectiva igualdad material ${ }^{9}$. Este razonamiento es particularmente fecundo cuando se trata de justificar la actividad probatoria del tribunal, en el sentido que el juez debería aportar prueba en los casos donde una de las partes aparece situada en un desnivel respecto de la contraria.

Así, Taruffo explica que es frecuente que los litigantes no estén en iguales condiciones, o al menos, en condiciones no comparables desde el punto de vista cultural y económico. Por lo general, los recursos económicos de una pueden ser limitados y su inversión en la actividad probatoria puede no estar equilibrada con la producción probatoria de la otra. Para que esta desigualdad no distorsione la obtención de la verdad por ser la parte más "fuerte" la única económicamente capaz de suministrar el material probatorio, es necesario dotar al juez de un rol activo, tanto en la clarificación de los hechos como en la producción de la prueba ${ }^{10}$. En similar sentido se pronuncia Barbosa Moreira, quien reconoce la desventaja en que se encuentra el litigante pobre en la producción de la prueba, dado que no cuenta con los recursos económicos, con el consiguiente desequilibrio en la posición procesal. Con el objeto de mitigar la desigualdad procesal y evitar esta distorsión, el juez debería asumir un rol activo en la recopilación del material probatorio, sin que dicha tarea implique sustituir la actividad primaria que le corresponde a las partes ${ }^{11}$. Para Cappelletti,

\footnotetext{
9 Así opinan, entre otros: TARuffo, Michele, "Investigación judicial y producción de prueba por las partes", Revista de Derecho de la Universidad Austral de Chile, Vol. XV, N 2, 2003, p. 210. Así parece refrendarlo para el ámbito latinoamericano FIx ZAMUDıO, Héctor, Constitución y proceso civil en Latinoamérica, Instituto de Investigaciones Jurídicas Universidad Nacional Autónoma de México, México, 1974, pp. 49 y 50, cuando entiende que la tendencia de los ordenamientos es conferir poderes y facultades al juzgador para orientar a las partes en el ejercicio de sus derechos, y además, para corregir y subsanar sus errores y deficiencias en sus defensas, particularmente cuando una de ellas puede considerarse más débil en un proceso determinado. Vid., también: Barbosa Moreira, José, "A funçao social do processo civil moderno e o papel do juiz e das partes da direçao e na instruçao do processo", Revista de Processo № 37, año X, 1985, p. 141 y ss. También puede verse: Devis Echandía, Hernando, "La iniciativa probatoria del juez en el proceso contemporáneo", Revista Iberoamericana de Derecho Procesa № 4, 1967, pp. 644 y siguientes, quien es categórico en afirmar que la consecución del principio de igualdad de armas se alcanza adjudicándole poderes para que triunfe la verdad y no la habilidad o el poder económico de una de las partes. Similar opinión sustenta Baur, Fritz, Publicaciones del Departamento de Derecho Procesal de la Universidad de Salamanca. La socialización del proceso, 1980, pp. 15 y 16, y Comoglıo, Luigi Paolo, "Direzione del processo e responsabilità del giudice", Rivista di Diritto Processuale No 4, 1981, pp. 17 y siguientes.

10 TARufFo, "Investigación", cit. nota. n. 9, pp. 210 y 211.

11 Barbosa, "A funçao", cit. nota. n. 9, p. 148.
} 
la actividad probatoria del juzgador muestra sus rasgos esenciales cuando una parte o ambas no han estado en situación de practicar pruebas, generalmente por razones de índole económicas que han impedido asegurarse una defensa suficientemente hábil y calificada. Con esto se lograría una igualdad sustancial de los litigantes favoreciendo una mejor decisión, o más precisamente, una decisión más justa ${ }^{12}$.

A finales del siglo XIX y principios del siglo XX, de la mano de Klein en Austria y Chiovenda en Italia (línea continuada por Calamandrei, Denti, Cappelletti y Taruffo), el Derecho Procesal comienza a promover la construcción de un proceso civil sobre la base de un principio de igualdad material de los litigantes, intentando superar el trato meramente formal que hasta ese momento se hacía. El punto de partida es la misma realidad judicial: por lo general, los litigantes no están en condiciones económicas y culturales de proveerse una defensa equivalente u homogénea. La calidad técnica de la defensa y la posibilidad de producir prueba dependían, en último término, de la condición económica de la parte; por ende, las posibilidades de éxito del menos habiente y del peor defendido disminuían en igual proporción de cuanto más pobre y peor defendido sea. Esta idea caló hondo en el Codice de Procedura Civile de 1942, donde en palabras de Calamandrei, "el propósito del legislador de hacer el nuevo proceso civil 'más accesible también a las personas humildes y desheredadas de fortuna' se revela, sobre todo, en las medidas con que se ha tratado de hacer prácticamente operativo y de garantizar en toda causa el principio de igualdad de las partes que en el viejo proceso no pasaba de ser, con frecuencia, una enunciación puramente teórica".$^{13}$ Con esto se intentaba que la igualdad jurídica que se predica del proceso no sea letra muerta, impidiendo que cediera frente a la desigualdad económica y cultural de los litigantes; en consecuencia, se creó una serie de mecanismos para colocar a la parte más débil en condiciones de paridad con la fuerte, de manera que la desigualdad de hecho no lesionara, efectivamente, a la igualdad jurídica. ${ }^{14}$

12 Cfr., Cappelletti, Mauro, La oralidad y las pruebas en el proceso civil, Ediciones Jurídicas EuropaAmérica, Buenos Aires, 1972, pp. 125 y 126. Si bien la idea de un juez asistencial nace con Klein, se expande al resto de Europa y Latinoamérica por medio de las obras de Chiovenda y su enorme influencia para la ciencia procesal. Vid., CHIOVENDA, Giuseppe, "Las reformas procesales y las corrientes del pensamiento moderno", Ensayos de Derecho Procesal Civil Vol. II, Ediciones Jurídicas EuropaAmérica, Buenos Aires, 1949, pp. 155 a 173.

13 Calamandrel, Piero, Derecho Procesal Civil, Tomo I, Ediciones Jurídicas Europa-América, Buenos Aires, 1986, p. 417.

14 Calamandrei, Derecho, cit. nota. n. 13, p. 418. Aun cuando parte de la doctrina italiana fue categórica en afirmar que el pretendido rol activo del juez fue más bien una aspiración que una realidad. Vid., Trocker, Nicolò, Processo civile e costituzione. Problemi di diritto tedesco e italiano, Giuffrè Editore, Milán, 1974, p. 729. 
La función asistencial y activa del juez en la contienda procesal se conectaba derechamente con una efectividad de la garantía de la defensa ${ }^{15}$, puesto que al litigante débil se le informa de sus derechos por parte del juez y es suplido en su inactividad cuando su situación cultural o económica no le permitía hacerse cargo del costo de la actividad probatoria. Con esta función la igualdad formal se transformaba en una igualdad sustancial, y el juez cumplía la misión de equilibrar la balanza jugando un rol activo.

Esta visión de la igualdad constituye una manifestación de la superación de la noción de Estado liberal de Derecho, y de la consecuente visión abstracta del individuo. Los ideales post Revolución Francesa forjaron una concepción formal de la igualdad (como igualdad ante la ley), que concibió a los individuos como sujetos cuyas diferencias no son recogidas por el Estado. Sin embargo, con el cambio al Estado Social de Derecho se produce la sustitución de la noción igualdad formal por una igualdad sustancial, que alcanza también al ámbito procesal. Para esta visión sólo hay trato igualitario cuando los litigantes están en homogénea posición frente a una norma o institución; por el contrario, cuando uno de los sujetos procesales está en una posición de desventaja en relación a su contrincante, el Estado debe desempeñar un rol activo en las tareas procesales que le corresponden a la parte débil para alcanzar la nivelación interpartes y lograr la paridad material. El juez deja de ser un mero espectador de la contienda para convertirse en un vivo protagonista, cuya actividad debe dirigirse a proteger a la parte débil.

Es un hecho que no puede cuestionarse el que la igualdad práctica difícilmente puede alcanzarse en términos de coincidir con el ideal de igualdad jurídica. Como lo afirma Montero Aroca, "muchas veces la lucha por la justicia se convierte en algo tan desigual como la vida social" ${ }^{16}$ en consecuencia, es probable que la idéntica posibilidad de facultades y de cargas y deberes no vaya unida a una idéntica capacidad de soportar las cargas y ejercer las facultades.

\section{Desigualdades procesales y ROL Del JueZ}

Hablar de desigualdad en el proceso no parece una tarea conceptualmente sencilla. Al respecto, pueden identificarse al menos tres parcelas donde es posible hablar de desigualdad entre los litigantes: en primer lugar, la desigualdad sustantiva, propia de la relación jurídico-material; en segundo lugar, la desigualdad económica, que pone a las partes es una disparidad significativa para satisfacer las cargas, y por último, la desigualdad técnica, aplicable a los casos

15 Así, entre otros: Trocker, Processo, cit. nota. n. 14, p. 729.

${ }^{16}$ Montero, Derecho, cit. nota. n. 1, p. 331. 
donde una de las partes presenta una ventaja derivada del dominio del hecho o de la cercanía con la fuente de prueba.

\section{Desigualdades sustantivas y actividad probatoria del juez}

Una de las razones que puede justificar un rol activo del juez en materia de prueba es la necesidad de acabar con el desequilibrio que admiten algunas relaciones jurídico-materiales. Estas relaciones se caracterizan por existir un fuerte desequilibrio en la capacidad de los sujetos de disciplinar la relación sustantiva, donde uno termina imponiendo el contenido de la relación material a la otra. Esta desigualdad, por lo general, presenta motivaciones de naturaleza económica ${ }^{17}$. Es el caso, por ejemplo, de la relación entre trabajador y empleador, consumidor y empresario, etc. Si bien es cierto que los ordenamientos jurídicos suelen regular especialmente los procesos que versan sobre este tipo de relaciones, me parece que no es posible justificar un aumento de la actividad probatoria del juez para lograr equilibrios sustantivos, puesto que puede comprometer gravemente la imparcialidad del juez.

Al contrario, es el Derecho material el que debe intentar superar esa desigualdad mediante normas protectoras de la parte más débil, ya sea prohibiendo inversiones convencionales de la carga de la prueba, estableciendo presunciones legales, dando la posibilidad de entablar acciones colectivas, estableciendo derechos irrenunciables, etc. Estos mecanismos son plenamente compatibles con la imparcialidad del juez, ya que no condicionan su actividad en el proceso (el juez se limita a aplicar la norma jurídica sustancial) y permiten alcanzar el ideal de justicia distributiva que debería gobernar estas relaciones jurídicas. No se trata de una igualdad por compensación o el establecimiento de una desigualdad en sentido contrario ${ }^{18}$, puesto que no se utiliza la norma procesal para lograr la equiparación, sino que es el mismo derecho material el que sirve para constatar y superar esa disparidad. Ambas partes tienen iguales posibilidades y cargas, y por tanto, la norma procesal cumple con la noción de igualdad.

En el proceso mismo rige para las partes un principio absoluto de igualdad de $\operatorname{armas}^{19}$, por ende, no puede justificarse alguna discriminación basada en la diversa condición de los sujetos en relación al derecho sustancial, ya que

\footnotetext{
17 Ambos casos podrían fundar un rol activo del juez.

${ }^{18}$ Expresiones utilizadas por Montero, Derecho, cit. nota. n. 1, p. 331. Este es el sentido de la igualdad que se pretende dar a algunas ramas del derecho como el laboral, del consumo o de familia, donde se intenta establecer una igualdad por compensación. Este tipo de técnica importa romper la igualdad procesal para corregir la desigualdad en la relación material y esa característica hace que sea una técnica desechable. Vid., además: SerRano, La prohibición, cit. nota. n. 4, p. 114.

${ }^{19}$ Como lo indica, Vázquez Sotelo, José Luis, "Los principios del proceso civil", Revista Justicia № 93, 1993, p. 610, las normas que regulan el proceso sólo pueden asegurar una igualdad formal y no una material.
} 
sólo es posible hablar de partes y no de "acreedor y deudor", "padre e hijo", etc. ${ }^{20}$ No es razonable pretender que la actividad del juez corrija la injusticia del contenido de la relación sustantiva.

Ahora bien, sustentar que no es posible justificar la actividad probatoria del juez en la protección de la parte más débil no significa, al mismo tiempo, decir que esa actividad probatoria es siempre contraria a la imparcialidad e igualdad procesal. Es indudable que la igualdad de armas favorece la conservación de la imparcialidad. El ordenamiento, al asegurar a los litigantes iguales posibilidades y cargas, limita considerablemente las posibilidades de que el juez actúe en el ámbito probatorio, aunque ciertamente tampoco lo excluye. Por eso, parte de la doctrina indica que la "construcción dialéctica del proceso, mediante las recíprocas alegaciones y pruebas y el principio de contradicción, salvaguarda la imparcialidad del juez".${ }^{21}$ Pero: ¿Rompe el principio de igualdad la actividad probatoria del juez?

La respuesta a esta interrogante debe ser planteada en una escala de intensidad en relación a los poderes asignados a los jueces. En los ordenamientos que potencian la actividad probatoria del juez, casi sin limitación, una actuación desmesurada del juez puede romper esa igualdad al liberar totalmente a las partes de las cargas, afectando de esa forma su imparcialidad ${ }^{22}$. Si la actividad probatoria del juez se encamina únicamente a la protección de la parte más débil, la peor defendida o menos astuta, se pondría en jaque su imparcialidad ${ }^{23}$. Éste dejaría de ser un tercero imparcial, para transformarse en asistente de una de las partes.

En aquellos ordenamientos que consagran poderes probatorios precisando límites es difícil considerar que cada vez que el juez desempeña una actividad probatoria esté rompiendo el principio de igualdad, beneficiando a una de las

\footnotetext{
${ }^{20}$ Cfr., Andolina; Vignera, I fondamento, cit. nota. n. 3, p. 120.

${ }^{21}$ Vázquez Sotelo señala que la "construcción dialéctica del proceso, mediante las recíprocas alegaciones y pruebas y el principio de contradicción, salvaguarda la imparcialidad del juez". VÁzQuEz, Los principios, cit. nota. n. 19, p. 605.

${ }^{22}$ Cabe indicar que no hay antecedentes históricos ni tampoco se conoce de procesos modernos donde el aumento en los poderes del juez haya sido inversamente proporcional a los derechos y actividad de los litigantes. Esto indica que jamás se ha intentado sustituir la actividad probatoria primaria de las partes por la del juez.

23 Así, Montero, Derecho, cit. nota. n. 1, p. 332; EtXeberRía Guridı, José, Las facultades judiciales en materia probatoria en la LEC, Tirant lo Blanch, Valencia, 2003, pp. 63 y 64; Bordalí SalamanCA, Andrés, "Los poderes del juez civil", en Proceso Civil. Hacia una nueva justicia civil, Editorial Jurídica de Chile, Santiago, 2007, p. 197 y Fazzalarl, Elio, "La imparzialità del giudice", Rivista di Diritto Processuale Vol. XXVII, 1972, pp. 193 a 203. También se muestra contrario a asignar al juez un rol activo en materia de pruebas sobre la base de entender que se logra una igualdad material de los litigantes: CAO, Umberto, "Esigenze sociali e individualismo nel processo civile", en Scritti in onore di G. P. Chironi, Vol. II, Bocca Editor, Torino, 1915, pp. 1 a 32.
} 
partes y perjudicando a la otra. Entiendo que bien delimitada no tendría por qué lesionarlo. Cuando la actividad probatoria se desarrolla en el marco de la audiencia preliminar, guiada bajo un criterio objetivo de completitud del material probatorio, el juez no está en condiciones de saber a ciencia cierta a qué parte va a beneficiar la prueba, por lo que resulta difícil justificar una ruptura del principio de igualdad o imparcialidad.

En este sentido, la tarea del juez en la recolección del material probatorio puede derivar de diferentes razones que no suponen un quiebre de la igualdad frente a las partes. Puede ser, por ejemplo, que el juez ingrese al proceso todas aquellas fuentes de prueba que las partes no han ingresado por una u otra causa. Las partes cuando deciden proponer y practicar prueba ponderan la fuente probatoria en relación a una expectativa razonable de resultado favorable; en consecuencia, no propondrán aquellos medios que puedan significar un riesgo para su situación procesal, ya sea porque sepan que no les dará un buen resultado o porque simplemente lo ignoran. El juez, en cambio, no hace ese ejercicio de valoración, y su decisión de ingresar la fuente omitida pasa por estimarla útil y pertinente para completar el haz probatorio y acercarse a la verdad ${ }^{24}$. Con todo, es claro que la iniciativa probatoria del juez no puede garantizar la obtención de la verdad, pero sí contribuye a acercar el proceso a ese ideal. En consecuencia, es una herramienta eficiente para disminuir las posibilidades de error de la decisión judicial, al aumentar el grado de probabilidad de que la decisión se corresponda con lo que efectivamente sucedió ${ }^{25}$.

\section{Desigualdades económicas y actividad probatoria del juez}

Nos encontramos ante un supuesto de desigualdad económica cuando una de las partes no posee los medios económicos suficientes para producir

\footnotetext{
${ }^{24}$ Me adscribo, por tanto, a una teoría muy difundida en parte de Europa y nuestro país, denominada "teoría de la justicia de la decisión", y que descansa en razones de evidente lógica: "parece, en efecto, intuitivo que la norma será aplicada injustamente, y sería, pues, violada, si las consecuencias que prevé se adjudicaran a un caso en que el hecho condicionante no se hubiere producido". TARUFFO, Michele, "Idee per una teoria della decisione giusta", en Sui Confini. Scritti sulla giustizia civile, II Mulino, Bolonia, 2002, pp. 224 y 225. Con todo, es evidente que las aguas se encuentran particularmente divididas al momento de asignarle una función a la prueba. Algunos sostienen que la finalidad de la prueba es la obtención de la verdad (entre otros: TARUfFo, Michele, La prueba, Marcial Pons, Madrid, 2008, p. 28, y BorDALI, "Los poderes", cit. nota. n. 23, pp. 192 y 193). Mientras que otros entienden que el fin de la prueba es la de convencer al juez acerca de la existencia de un hecho. (Entre otros: Palomo Vélez, Diego, "Proceso civil oral: ¿Qué modelo de juez requiere?", en Proceso Civil. Hacia una nueva justicia civil, Editorial Jurídica de Chile, Santiago, 2007, p. 244, y De La Oliva Santos, Andrés, Derecho Procesal Civil. El proceso de declaración, Editorial Universitaria Ramón Areces, Madrid, 2004, p. 165). Este debate supera con creces el propósito de estas líneas.

${ }^{25}$ TARUfFo, La prueba, cit. nota. n. 24, p. 28, y FerRer Beltrán, Jordi, La valoración racional de la prueba, Marcial Pons, Madrid, 2007, p. 29.
} 
la prueba necesaria para acreditar los hechos, situación que le impide, de facto, proponer la prueba pertinente y relevante (un trabajador frente a una gran empresa).

Es evidente que no se puede propugnar una homogeneidad absoluta entre los contradictores -que además sería imposible de alcanzar en el plano fáctico-; por lo tanto, hay que aceptar la posibilidad de que exista una disparidad, pero ésta no debe ser tal de condicionar la efectiva capacidad de levantar las cargas y ejercer las facultades. El límite a la desigualdad está en la indefensión procesa $^{26}$. En otras palabras, para el Derecho Procesal es indiferente la desigualdad económica en que se sitúen los litigantes, puesto que rige la igualdad frente a las facultades y cargas. Sin embargo, cuando la disparidad afecta la capacidad de una de las partes de levantar sus cargas y ejercer sus facultades, ésta debería ser corregida. Como lo explica RodríGuez García, "la indefensión incompatible con la tutela judicial efectiva puede originarse cuando se sitúa a las partes en una posición de desigualdad o si se impide la aplicación efectiva del principio de contradicción mediante el adecuado desarrollo de la dialéctica procesal; desigualdad real e inaplicación práctica del principio mencionado puede producirse cuando priva de la posibilidad efectiva de la dirección de Abogado a quien carece de medios económicos" ${ }^{27} \mathrm{O}$ como diría otra doctrina: "desigualdad de los medios de defensa e indefensión son dos caras de la misma moneda, se implican mutuamente" ${ }^{\prime 28}$

Sin embargo, la corrección a esa desigualdad no debe ser entregada al juez, cuya actividad en el proceso se encuentra condicionada por su calidad de tercero imparcial. Es el Estado, por medio de los sistemas de asistencia jurídica gratuita, el que debe corregir esa disparidad, colocando de cargo del erario fiscal todo o parte

\footnotetext{
26 Como lo indica Rodríguez García, Nicolás, Justicia gratuita: un imperativo constitucional, Editorial Comares, Granada, 2000, p. 57, si al que no tiene medios no se le da la oportunidad de obtener una defensa efectiva de sus derechos se le produciría una situación de genuina indefensión. En efecto, en este sentido, los costos de acceso a la justicia no deberían ser obstáculos insalvables para una tutela efectiva de los derechos e intereses legítimos, cuestión que se produce cuando se lesiona el derecho de defensa al impedirse a una de las partes de producir prueba por no poder asumir los costos de la misma. Vid., también: Carreras del Rincón, Jorge, Comentarios a la doctrina procesal civil del Tribunal Constitucional y del Tribunal Supremo. El artículo 24 de la Constitución Española. Los derechos fundamentales del justiciable, Marcial Pons, Madrid, 2002, p. 208, quien reconoce expresamente que las normas de igualdad en el proceso cobran valía cuando el derecho de defensa de los litigantes es lesionado.

27 Rodríguez, Justicia, cit. nota. n. 26, p. 57.

${ }^{28}$ Serrano, La prohibición, cit. nota. n. 4, p. 109. Puede verse también en relación a la justicia gratuidad y la obtención de la igualdad: PACheco Guevara, Andrés, "Justicia gratuita y tutela judicial efectiva", en Justicia gratuita. Cuadernos de Derecho Judicial, Consejo General del Poder Judicial, Madrid, 1995, pp. 11 a 14.
} 
de los costos de la litigación ${ }^{29}$. Como opina la doctrina, "la única forma práctica de lograr un equilibrio efectivo de las partes en el proceso consiste en garantizar a la parte más débil, además de una exención de las costas judiciales -cuando existen-y las de carácter procesal, una asistencia letrada obligatoria y gratuita, que le permita superar su situación de inferioridad frente a la otra, cuando esta última posee mayores elementos económicos, y por tanto, de asesoramiento" ${ }^{30}$ Esta idea se encuentra consolidada a nivel de la jurisprudencia del Tribunal Constitucional Español, que ha postulado frecuentemente que la finalidad de la justicia gratuita "es la de asegurar la efectiva realización de los principios de igualdad de las partes y de contradicción que impone a los órganos judiciales el deber positivo de evitar desequilibrios entre la respectiva posición procesal de las partes, o limitaciones en la defensa que puedan inferir a alguna de ellas un resultado de indefensión, prohibido en todo caso por el Art. 24.1 CE". ${ }^{31}$.

En este aspecto, un mecanismo efectivo para hacer frente a la desigualdad material es adoptar un sistema de defensa jurídica gratuita capaz de absorber tanto la necesidad de una defensa técnica adecuada, como los costos que implica la litigación, en especial, los costos de las pruebas. Esta debería ser la herramienta para superar la diferente condición económica de las partes en la producción de la prueba relevante, pero nunca la asignación al juez de una tarea ajena a su posición de equidistancia respecto de las partes, que pueda sacrificar su imparcialidad y romper con la igualdad ${ }^{32}$.

No obstante, los sistemas de defensa gratuita para los juicios civiles no han concitado el interés de la doctrina ni menos del Estado, y esto sí es preocupante. $\mathrm{Si}$ el Estado tiene el deber de asegurar al ciudadano una defensa real y efectiva de manera de hacer posible la igualdad jurídica, entonces urge discutir acerca de qué forma se logra ese anhelo. La realidad muestra que las Corporaciones de Asistencia Judicial no son capaces de solventar íntegramente la defensa en juicio más allá de la defensa técnica letrada, como tampoco tienen los medios y equipo técnico para los litigios de complejidad. De ahí la necesidad de empezar a preocuparse seriamente de la asistencia letrada obligatoria, y su relación con el principio de igualdad y el derecho de defensa.

29 Gómez Colomer, Juan, "El nuevo régimen de beneficio de la asistencia jurídica gratuita", La Ley № 2,1996, p. 1579, define el derecho a la justicia gratuita señalando que se trata "de un derecho público subjetivo de carácter estrictamente procesal por su finalidad y estructura y rango constitucional, en virtud del cual la parte procesal, actual o futura, que acredite insuficiencia de recursos para ejercer su derecho de acción u oponer su resistencia (...) viene eximida totalmente o en parte, de abonar los gastos que el proceso origine".

${ }^{30}$ FIx, Constitución, cit. nota. n. 9, p. 68.

31 Sentencia del Tribunal Constitucional Español 174/2009, de 16 de julio.

32 De ahí que la doctrina entienda que el beneficio de justicia gratuita tiene un asidero constitucional en el principio de igualdad. Vid., Gómez, El nuevo, cit. nota. n. 29, p. 1579. 


\section{Desigualdad técnica y actividad probatoria del juez}

Por otro lado, la superioridad técnica de una de las partes también puede ser suficiente para considerar a una parte débil en relación a la otra estimada fuerte, especialmente, cuando la complejidad técnica de los hechos y la posibilidad de producir prueba es particularmente más difícil para una de las partes. Es el caso, por ejemplo, del paciente que demanda la negligencia de su médico.

Ahora bien, hay que precisar que la complejidad técnica con que una de las partes puede enfrentarse a la prueba de un hecho no es indiferente a la jurisdicción. Cuando una de las partes tiene el dominio completo respecto del hecho (conoce de mejor forma el hecho controvertido), y está en una situación de cercanía respecto de las fuentes de prueba, también se genera una hipótesis de desigualdad, no económica, pero sí técnica. Es evidente que esto no significa que al juez se le adjudique algún rol relevante en materia probatoria, aunque sí puede utilizar algunas herramientas para trasladar la carga de la prueba a la parte "fuerte" desde el punto de vista probatorio. ${ }^{33}$ En efecto, coherente con el Art. 265 del PCPC ${ }^{34}$ frente a esa desigualdad, el juez puede invertir la carga de la prueba, colocándola sobre la parte que tiene un mejor dominio del hecho o que está más cerca de la prueba ${ }^{35}$. Esa regla no genera ninguna objeción ni quiebre de la igualdad, en la medida que se informe con la antelación debida y permita a las partes proponer la prueba necesaria para vencer la carga asignada. ${ }^{36}$

\footnotetext{
${ }^{33}$ Cualquiera sea la herramienta que pueda utilizar el juez, es fundamental tener presente que sólo la desigualdad técnica capaz de lesionar el derecho de defensa provocando indefensión es susceptible de justificar el empleo de esas herramientas correctoras. Por tanto, si una de las partes está en mejores condiciones de probar, esa sola circunstancia no amerita igualar probatoriamente a las partes, sino cuando esa diferencia coloca a una de ellas en situación de indefensión.

${ }^{34}$ Art. 265. Carga de la prueba. Corresponde la carga de probar los fundamentos de hecho contenidos en la norma jurídica a la parte cuya aplicación le beneficie, salvo que una disposición legal expresa distribuya con criterios especiales diferentes la carga de probar los hechos relevantes entre las partes. El tribunal podrá distribuir la carga de la prueba conforme a la disponibilidad y facilidad probatoria que posea cada una de las partes en el litigio, lo que comunicará a la parte con la debida antelación para que ella asuma las consecuencias que le pueda generar la omisión de información de antecedentes probatorios o de rendición de la prueba que disponga en su poder.

35 Vid., Fernández LóPEZ, Mercedes, La carga de la prueba en la práctica judicial civil, Editorial La Ley, Madrid, 2006, pp. 142 y ss., y GonZÁlez GRANDA, Piedad, "Los criterios de disponibilidad y facilidad probatoria en el sistema del artículo 217 de la LEC", en Carga de la prueba y responsabilidad civil, Tirant lo Blanch, Valencia, 2006, pp. 55 y ss.

36 No puedo dejar de apuntar que este es un problema que deberá solucionar el PCPC. En efecto, la utilización de los criterios correctores de la carga de la prueba tienen aplicación en la audiencia preliminar, momento en el cual el juez puede decidir que cierto hecho, en principio, de carga de una de las partes, pase a la otra. Sin embargo, los litigantes no pueden modificar ni agregar prueba nueva en esa audiencia, dado que ha operado la preclusión. Esto podría generar serios problemas en orden a la defensa de los litigantes.
} 
En consecuencia, el artículo $5^{\circ}$ del PCPC, en tanto exige que el juez vele por mantener la igualdad procesal, debería ser una fuerte justificación para aplicar los criterios de corrección de la carga de la prueba cuando observe una extrema dificultad técnica para soportar las cargas en términos de lesionar el derecho de defensa. En simples palabras, la desproporción considerable en la capacidad de las partes de asumir y satisfacer la carga de la prueba que genere una situación de indefensión puede justificar su inversión.

Por último, otra técnica que también puede palear las dificultades en que se enfrenta una de las partes en relación a la prueba es el manejo adecuado del estándar de prueba. Se trata de considerar que aquellas hipótesis de hecho donde una de las partes está más cercana a la fuente o tiene un mejor dominio del hecho pueden considerarse probadas con pruebas de menor intensidad epistémicas, en relación a hipótesis que pueden considerarse "normales". De lo contrario, de no producirse esta concesión, se le pondría a una de las partes una carga probatoria exageradamente onerosa respecto a su efectiva capacidad técnica de soportarla. En este caso, la mantención del principio de igualdad opera en la etapa de valoración de la prueba.

\section{De leGe lata. El principio de igualdad, el PCPC Y LA INICIATIVA PROBATORIA DEL JUEZ}

En los acápites anteriores he tratado de justificar por qué la igualdad sustancial no es un valor que pueda perseguirse en el proceso a través de la actividad probatoria del juez. También he dado cuenta que la iniciativa probatoria no supone una ruptura del principio de igualdad formal. Ahora quisiera, por un lado, justificar dogmáticamente a la luz del PCPC que la actividad probatoria del juez no puede estar destinada a superar las diferencias económicas de los litigantes en la posibilidad de levantar las cargas probatorias, esto es, que el juez no puede justificar su iniciativa probatoria en la condición económica de una de las partes. Junto a lo anterior, quisiera proponer algunos elementos que considero relevantes para que la actividad probatoria del juez respete íntegramente la igualdad de los litigantes. Esta última indagación se justifica en la medida que se constata que la mayoría de los ordenamientos contemporáneos reconocen al juez un poder discrecional y amplio de aportación de prueba, por lo general, sin límites legalmente definidos. Este es el caso de nuestro PCPC.

\section{El Art. $5^{\circ}$ del PCPC no puede justificar una actividad probatoria del juez}

Conforme he sostenido en este trabajo, no es factible entender que el rol activo del juez en materia de pruebas tenga relación con la obtención de una igualdad entre los litigantes, de manera que el juez deba decantarse a favor de 
la parte débil. Esta interpretación, además de insostenible en abstracto, no es posible justificarla en el plano del PCPC, y ello por varias razones:

a). Las normas que confieren poderes discrecionales al juez civil son normas de fin, esto es, "se limitan a imponer a los Ilamados a aplicarlas un fin determinado absteniéndose de determinar de antemano la conducta a seguir para alcanzar éste" ${ }^{\prime \prime 37}$. Estas se caracterizan por no determinar la manera en las que debe perseguirse el fin, por lo que el órgano decidor debe realizar juicios acerca de cuál es la mejor forma para optimizar la finalidad prevista en la regla ${ }^{38}$. En este sentido, el Art. 18 $N^{\circ} 4$ del PCPC coloca como thelos de la actividad probatoria del juez la obtención de la verdad de los hechos controvertidos y no la igualdad sustancial de los litigantes. Lo que debe buscar el juez es la verdad de unos hechos que funcionan como presupuestos de la norma a aplicar, cuestión que nada tiene que ver con efectuar un rol asistencial a la parte más débil para lograr igualdades sustanciales.

Esta distinción no es meramente teórica, sino más bien práctica. Si el juez utiliza su potestad probatoria para una finalidad diferente a la que estaba prevista en la norma podría darse un supuesto de desviación de poder, con todas sus consecuencias aparejadas.

b). La única disposición que se coloca en la situación de inferioridad económica o de carencia de medios de una de las partes es el Art. 289 inciso final ${ }^{39}$, que permite al tribunal, una vez acreditada la carencia de recursos necesarios para pagar los honorarios del perito, solicitar la elaboración de un informe de peritos por un órgano público u organismo que reciba aportes del Estado, siempre y cuando el juez lo estime indispensable para la adecuada resolución del conflicto. En este caso, la prueba pericial corre de cargo del Estado cumpliendo una evidente tarea asistencial de la parte que no puede franquearse la prueba por carecer de medios, sin embargo, debe operar a petición de parte, esto es, previa excitación del particular. El juez no puede-porque no lo autoriza la norma-proponer prueba porque una de las partes no tiene las condiciones económicas para hacerlo.

Me parece que la solución que adopta el PCPC es bastante razonable, en la medida que pone de cargo de la parte acreditar la insuficiencia en los recursos económicos y la petición de prueba. Sin embargo, quizá la solución más adecuada para una completa igualdad de posibilidades en la producción de la prueba, habría sido que la pericia sea evacuada no tanto por un organismo

${ }^{37}$ Fernández Rodríguez, Tomás-Ramón, Del arbitrio y de la arbitrariedad judicial, lustel, Madrid, 2005, p. 57.

38 Vid., Lifante Vidal, Isabel, "Dos conceptos de discrecionalidad jurídica", Doxa № 25, 2002, p. 433 y siguientes.

${ }^{39}$ Art. 289 inciso final dispone. "Asimismo, cuando la parte respectiva haya acreditado que carece de los recursos necesarios para pagar los honorarios del perito el juez, a petición de ésta, podrá solicitar la elaboración de un informe de peritos a algún órgano público u organismo que reciba aportes del Estado, cuando lo estime indispensable para la adecuada resolución del conflicto". 
público o dependiente del Estado, sino por un profesional independiente y competente cuyos honorarios sean determinados prudencialmente por el juez y pagados, en definitiva, por el Estado, sin perjuicio de la resolución final sobre las costas. Es una solución más adecuada en la medida que las especialidades de las pericias pueden escapar en algunas oportunidades a la competencia de los profesionales que trabajan para el Estado.

Con todo, es preciso mencionar que la posibilidad de que el Estado solvente el costo de la prueba viene dada solamente para la prueba pericial, sin que pueda extenderse a los medios de prueba. Por ende, no parece razonable que el juez deba asumir una tarea asistencial que el mismo PCPC recorta a un medio de prueba concreto, máxime cuando éste opera a petición de parte.

c). Otra razón para descartar que la obtención de la igualdad sustancial sea el objetivo de la actividad probatoria es el propio tenor literal de la disposición. La norma en cuestión autoriza al juez para velar por la "mantención" de la igualdad de las partes. Es decir, supone que las partes ya están en un plano de igualdad, de ahí que el juez deba simplemente mantenerla. No se trata, por tanto, de alcanzar o lograr la igualdad sustancial, sino que debe remover los obstáculos que impidan -de hecho o de derecho-, gozar de las posibilidades de acción y defensa que el legislador ha reconocido a ambos litigantes.

Por lo expuesto, creo que la función del juez no es alcanzar la igualdad con la actividad probatoria, sino promover y articular un contradictorio que permita a las partes gozar de iguales posibilidades de acción y reacción para influenciar el contenido de la decisión final.

d). Por otro lado, reconocerle al juez un rol asistencial en materia probatoria, comprometiéndose con la situación débil y desmejorada de una de las partes, sería adjudicarle una tarea que carece de todo antecedente histórico en nuestro Derecho nacional. Incluso en materia de familia, donde no obstante tratarse de materias indisponibles, no le corresponde al juez asumir una tarea de tutela a los más débiles, sino más bien garantizar la protección de valores supraindividuales a través de la obtención de la verdad de los hechos ${ }^{40}$. En este mismo sentido la idea de igualdad sustancial es en cierta forma ajena no sólo a la historia procesal chilena, sino también al ámbito constitucional, donde parece reconocerse la noción de paridad formal entendida más precisamente como igualdad de armas, es decir, como igualdad de trato por los tribunales de justicia. ${ }^{41}$

40 Hunter Ampuero, Iván, Las potestades probatorias del juez de familia, LegalPublishing, Santiago, 2008, pp. 52 y 53, para quien la mejor garantía de protección de los sujetos débiles es que el proceso pueda acercarse lo máximo posible a la verdad, en la medida que ello asegura, en parte, la justicia de la decisión jurisdiccional.

${ }^{41}$ Así quedó plasmado en la Sesión № 100 de la C.E.N.C., de 6 de enero de 1975. Vid., Evans De LA CuAdra, Enrique, Los Derechos Constitucionales, Tomo II, Editorial Jurídica de Chile, $3^{\text {a }}$ edición, 1999, p. 140. 


\section{Algunas claves para la plena compatibilidad entre actividad probatoria del juez e igualdad procesal}

No es lógico entender que cada vez que el juez propone prueba está perdiendo su imparcialidad. Creo, no obstante, que para mantener la igualdad procesal y no afectar la imparcialidad del juez, es posible indicar algunos elementos que deben estar presentes en la actividad probatoria del juez.

a). Un aspecto clave para identificar el ejercicio de la actividad probatoria del juez es aceptarla como poder o potestad y no como un deber. Resulta difícil entender que se respeta la igualdad procesal cuando el juez tiene el deber de proponer prueba, ya que en este caso se sustituye la carga probatoria ${ }^{42}$ y además la iniciativa judicial se desentiende de toda actividad previa de los litigantes. Un deber judicial en el ámbito de la prueba saca al juez de su calidad de tercero supra partes.

Con todo, las normas procesales que consagran la iniciativa probatoria del juez no imponen un deber jurídico, dado que carecen de una sanción directa e inmediata frente a su no cumplimiento, y además, no imponen la necesidad jurídica de actuar de una u otra forma ${ }^{43}$. Por lo general, se trata de normas que confieren al juez un espacio de libertad más o menos extenso para decidir qué hacer con su iniciativa probatoria. Por lo mismo, no definen la observación de una determinada conducta al interior del proceso ni tampoco la ejecución de una precisa actividad procesal.

b). Otro aspecto a cuidar para mantener la igualdad e imparcialidad es el carácter de subsidiaria o complementaria de las pruebas del juez, en relación a la iniciativa de la parte. Esto quiere decir que la actividad probatoria del tribunal viene a cerrar el catálogo de fuentes de prueba disponibles, integrando el material probatorio con aquellas fuentes que las partes no han querido ingresar por uno u otro motivo. Para no romper con la igualdad, la regla debería ser precisamente esa y no otra: prueba del juez, previa prueba de las partes ${ }^{44}$.

Esto quiere decir que la prueba ofrecida por el juez es residual al contradictorio entre las partes ${ }^{45}$, de manera tal que sean ellas las que desplieguen los

42 En palabras resumidas de SeNTIS, la carga procesal termina ahí donde hay un deber del juez. Cfr. Sentís Melendo, Santiago, "Perención de la instancia y carga procesal", en Estudios de Derecho Procesal I, Ediciones Jurídicas Europa-América, Buenos Aires, 1967, p. 352

43 Montoro Ballesteros, Alberto, El deber jurídico, Cuadernos de Teoría Fundamental del Derecho, № 14, Murcia, 1993, p. 8.

${ }^{44}$ Respetar esta regla es esencial, y su inclusión como límite se justifica cuando se observa el Art. 18 $N^{\circ} 4$ del PCPC, que autoriza al juez a proponer prueba sin vincularla a la actividad probatoria previa de las partes. Así, una lectura simple de esta norma, podría justificar una amplia actividad probatoria del juez, lo que ciertamente no es ni puede ser el deseo del legislador.

45 TARZIA, Giuseppe, "Poteri delle parti e poteri del giudice", en Problemi del processo civile di cognizione, Cedam, Padova, 1989, p. 363, en cierta medida invierte el fundamento, puesto que para sustentar 
mejores $-y$ por cierto muy interesados- esfuerzos probatorios. Esto asegura, por un lado, un mejor resultado de la prueba, y por el otro, que se mantenga la igualdad entre las partes, puesto que la actividad probatoria tendría lugar una vez que se ha respetado el ejercicio de las facultades procesales.

c). También es razonable entender que la igualdad jurídica se respeta cuando el ordenamiento frente a la iniciativa probatoria del juez permite realizar íntegramente el contradictorio. El contradictorio permitirá efectuar un control sobre el carácter subsidiario a la proposición de prueba de la parte, de manera de no suplirlas en las cargas impuestas por la ley ${ }^{46}$.

Con todo, en el PCPC el contradictorio aparece expresamente consagrado como límite a la actividad probatoria del juez en su manifestación del derecho de defensa. El método dialéctico no es solamente una elección de política procesal, sino una garantía epistemológica para la obtención de la verdad; entonces el ejercicio de los poderes del juez no puede prescindir del respeto al contradictorio $^{47}$. La iniciativa probatoria debe respetar el derecho de defensa, cuestión que implica tener en consideración al menos cuatro aspectos: en primer lugar, las partes deben tener la posibilidad de deducir prueba en contraste a la prueba propuesta por el juez ${ }^{48}$; en segundo lugar, se debe discutir en forma preventiva la admisibilidad de la prueba ex officio; en tercer lugar, las partes deben tener la posibilidad de discutir sobre la eficacia de la prueba propuesta por el juez, y en cuarto lugar, los litigantes deben temer la opción de actuar en contradicción al momento de practicarse la prueba.

la necesidad de un contradictorio entre las partes en la formación de la prueba parte del carácter subsidiario, complementario e integrativo de la prueba ex officio. En otras palabras, dado que la prueba ex officio es subsidiaria entonces es necesario proceder previa contradicción probatoria. La regla, sin embargo, es la contraria. Es el contradictorio previo en la formación de la prueba lo que condiciona y determina el carácter complementario de la prueba propuesta por el juez. Si bien puede justificarse por razones excepcionales la intervención del juez en materia probatoria, tampoco le corresponde efectuar una tarea que implique distorsionar el resultado de la prueba generada por medio del contradictorio entre las partes: prueba, contraprueba, exámenes y contraexamen, etc., es decir, el método dialéctico en la reconstrucción de los hechos debería ser la regla ideal para acercarse a la verdad o falsedad de un hecho. De ahí que, como lo indica la doctrina, "se adquiere un mayor grado de conocimiento de los hechos de la causa cuanto más elevado (no sólo del punto de vista cuantitativo) es el contradictorio garantizado a las partes". CARRATTA, Antonio, "Funzione dimostrativa della prova (verità del fatto nel processo e sistema probatorio)", Rivista di Diritto Processuale, LVI, № 1, 2001, p. 98.

46 Vid., Tarzia, Giuseppe, "Problemi del contraddittorio nell' istruzione probatoria civile", Rivista di Diritto Processuale, № 3 1984, p. 644.

47 UBERTIS, Giulio, "Neutralità metodologica del giudice e principio di acquisizione processuale", Rivista Italiana di Diritto e Procedura Penale No 50 2007, p. 26.

48 En contra, MONTESANO, Luigi, "Le prove disponibili d’ufficio e l’imparzialità del giudice civile", Rivista Trimestrale di Diritto e Procedura Civile 1978, p. 870, quien sostiene que la posibilidad de rendir prueba por la parte afectada con la iniciativa judicial es una hipócrita garantía del contradictorio y del derecho de defensa, puesto que no legitima la actividad probatoria del juez. El contradictorio, según el autor, se desarrolla entre las partes por medio de un diálogo constante, y no entre éstas y el juez. 
Nuevamente, el PCPC tiene un desafío pendiente, puesto que si la actividad probatoria del tribunal se efectúa en la audiencia preliminar, en ese momento las partes no pueden ofrecer nuevos elementos probatorios. Si la norma del Art. $18 \mathrm{~N}^{\circ} 4$ del PCPC establece como límite de la actividad probatoria el respeto al derecho de defensa, parece lógico que las partes tengan el derecho a ofrecer prueba destinada a desvirtuar la aportada por el juez. De lo contrario, el respeto al derecho de defensa sería sólo nominal, y no real y efectivo. En consecuencia, me parece importante introducir una norma que permita a las partes ofrecer material de conocimiento cuando el juez, en la audiencia preliminar, actúa su potestad probatoria.

En definitiva, es posible afirmar que lo pretendido a través de la formulación obligatoria del contradictorio es evitar que el interés público que existe de llegar o acercarse a la verdad para solucionar el conflicto jurídico, pueda comprometer el derecho de defensa de las partes, el derecho a rendir contraprueba o la imparcialidad del juzgador. ${ }^{49}$

\section{CONCLUSIONES}

El PCPC contiene una serie de normas que hasta el momento habían sido únicamente objeto de un estudio académico con escasa -por no decir inexistente- repercusión práctica. Este es el caso de la igualdad de armas, cuya tutela en el proceso está encomendada al juez. Convencionalmente, la igualdad suele ser tratada desde dos puntos de vista: por un lado, como mandato dirigido al legislador que representa la exigencia de igualdad de facultades y cargas entre los litigantes, y por el otro, como mandato dirigido al juez, entendido como deber de promoción del contradictorio.

La actividad probatoria del juez y su pretendido rol asistencial fueron promovidos en Austria por Klein e Italia por Chiovenda, influyendo en parte de la doctrina latinoamericana que pretendió hacer del juez un asistente de la parte más débil, justificando un rol activo en materia probatoria. Esta doctrina se justifica en la medida que se constata que en el proceso los litigantes suelen presentar importantes diferencias económicas que le impiden, con cierta frecuencia, asumir exitosamente las cargas procesales. No obstante, el respeto a la imparcialidad e igualdad de armas impiden que el juez pueda asumir un rol a favor de la parte más débil de la relación.

En efecto, el ordenamiento jurídico se vale de otras herramientas para enfrentar la desigualdad en que pueden encontrarse los litigantes frente a la prueba. Así, ante la desigualdad económica están los sistemas de defensa gra-

${ }^{49}$ Vid., en similar sentido: Comoglıo, Luigi Paolo, "Garanzie minime del 'giusto processo' civile negli ordenamenti latinoamericani", Rivista di Diritto Dell Integrazione e Unificacione del Diritto in Europa e in América Latina $\mathrm{N}^{\circ}$ 17, 2004, p. 223. 
tuita en los que el Estado asume los costos de la defensa técnica y de la prueba. En otros casos, cuando la desigualdad se da en la relación jurídico-sustancial, el Estado la corrige a través de normas protectoras de la parte débil, normas que deben situarse en el plano sustantivo, más no en lo procesal. Por último, ante la desigualdad técnica, el ordenamiento se vale de diferentes herramientas como la inversión de la carga de la prueba o la utilización del estándar de prueba. En todos estos casos, es necesario que la desigualdad sea capaz de afectar la defensa del litigante generando indefensión. En consecuencia, el límite a la desigualdad de los litigantes se encuentra en la indefensión. Sólo una desigualdad capaz de afectar el derecho de defensa de la parte puede justificar su eliminación.

Una interpretación sistemática y coherente de la igualdad en relación a la actividad probatoria del juez en el PCPC, confirma la regla de que el juez no tiene justificación para desempeñar un rol activo en función de la parte más débil. Por el contrario, las reglas que consagran poderes atendido su carácter de normas de fin, sólo legitiman alcanzar el fin previsto en la misma (la obtención de la verdad), y otros que incluso son ajenos a la tradición jurídico-procesal (la igualdad material). Por último, es necesario tener presente que la iniciativa probatoria del tribunal debe compatibilizarse con la igualdad procesal. Esto supone concebirla como una potestad (poder) de carácter subsidiario o complementario, ejercitada con una plena realización del contradictorio.

\section{BibLIOGRAFíA}

Andolina, Italo; Vignera, Giuseppe, I fondamento costituzionali della giustizia civile. Il modello costituzionale del processo civile italiano, Giappicchelli Editore, Torino, 1997, p. 113.

Asencio Mellado, José, Introducción al Derecho Procesal, Tirant lo Blanch, Valencia, 1997.

Barbosa Moreira, José, "A funçao social do processo civil moderno e o papel do juiz e das partes da direçao e na instruçao do processo", Revista de Processo $N^{0} 37$, año X, 1985.

BAUR, Fritz, Publicaciones del Departamento de Derecho Procesal de la Universidad de Salamanca, La socialización del proceso, Salamanca, 1980.

Bordalí Salamanca, Andrés, "Los poderes del juez civil", en Proceso Civil. Hacia una nueva justicia civil, De la Oliva Santos, Andrés, y Palomo, Diego (Coords.), Editorial Jurídica de Chile, Santiago, 2007.

Calamandrel, Piero, Derecho Procesal Civil, Tomo I, Ediciones Jurídicas EuropaAmérica, traducción de Santiago Sentis Melendo, Buenos Aires, 1986.

CAO, Umberto, "Esigenze sociali e individualismo nel processo civile", en Scritti in onore di G. P. Chironi, Vol. II, Torino, Bocca Editor, 1915. 
Cappelletti, Mauro, La oralidad y las pruebas en el proceso civil, Traducción de Sentis Melendo, Santiago, Ediciones Jurídicas Europa-América, Buenos Aires, 1972.

CarreRAs del Rincón, Jorge, Comentarios a la doctrina procesal civil del Tribunal Constitucional y del Tribunal Supremo. El artículo 24 de la Constitución Española. Los derechos fundamentales del justiciable, Marcial Pons, Madrid, 2002.

ChIOvendA, Giuseppe, "Las reformas procesales y las corrientes del pensamiento moderno", en Ensayos de Derecho Procesal Civil, traducción de Santiago Sentis Melendo, Vol. II, Ediciones Jurídicas Europa-América, Buenos Aires, 1949.

Comogııo, Luigi Paolo, "Direzione del processo e responsabilità del giudice", Rivista di Diritto Processuale No 4, 1981.

, "Garanzie minime del 'giusto processo' civile negli ordenamenti latinoamericani", Rivista di Diritto Dell'Integrazione e Unificacione del Diritto in Europa e in América Latina No 17, 2004, pp. 213 a 227.

Cortés Domínguez, Valentín, "La Constitución española y los principios rectores del proceso civil", en Principios constitucionales del proceso civil, CGPJ, Madrid, 1993.

Cortés Domínguez, Valentín, Introducción al Derecho Procesal (con Moreno Catena), Tirant lo Blanch, Valencia, 2003.

Couture, Eduardo, Fundamentos del derecho procesal civil, tercera edición, ediciones Depalma, Buenos Aires, 1988.

De La Oliva Santos, Andrés, Derecho Procesal Civil. El proceso de declaración, (con Díez-Picazo Jiménez, Ignacio), tercera edición, Editorial Universitaria Ramón Areces, Madrid, 2004.

Devis Echandía, Hernando, "La iniciativa probatoria del juez en el proceso contemporáneo", Revista Iberoamericana de Derecho Procesal № 4, 1967.

Do PASSO, Antonio, "Il principio del contraddittorio come diritto influenza e dovere di dibattito". Rivista di Diritto Processuale, LX, № 2, 2005.

ETXEBERRÍA GURIDI, José, Las facultades judiciales en materia probatoria en la LEC, Tirant lo Blanch, Valencia, 2003.

Evans de la Cuadra, Enrique, Los Derechos Constitucionales, Tomo II, Editorial Jurídica de Chile, 1999.

Fazzaları, Elio, "La imparzialità del giudice", Rivista di Diritto Processuale, Vol. XXVII, 1972.

FERNÁNDEZ LóPEZ, Mercedes, La carga de la prueba en la práctica judicial civil, Editorial La Ley, Madrid, 2006.

Fernández Rodríguez, Tomás-Ramón, Del arbitrio y de la arbitrariedad judicial, lustel, Biblioteca Jurídica Básica, Madrid, 2005. 
Ferrer Beltrán, Jordi, La valoración racional de la prueba, Marcial Pons, Madrid, 2007.

Fix Zamudıo, Héctor, Constitución y proceso civil en Latinoamérica, Instituto de Investigaciones Jurídicas Universidad Nacional Autónoma de México, México, 1974.

Gómez Colomer, Juan, "El nuevo régimen de beneficio de la asistencia jurídica gratuita", La Ley No 2, 1996.

GonzÁlez Granda, Piedad, "Los criterios de disponibilidad y facilidad probatoria en el sistema del artículo 217 de la LEC", en Carga de la prueba y responsabilidad civil, Tirant lo Blanch, Valencia, 2006.

Hunter Ampuero, Iván, Las potestades probatorias del juez de familia, Legalpublishing, Santiago, 2008.

Lifante VIDal, Isabel, "Dos conceptos de discrecionalidad jurídica", Doxa $N^{\circ} 25,2002$.

Montero Aroca, Juan, Derecho Jurisdiccional I, Parte General (con Gómez Colomer, Montón Redondo y Barona Vilar), Tirant lo Blanch, Valencia, 2003.

Montesano, Luigi, "Le prove disponibili d’ufficio e l’imparzialità del giudice civile", Rivista Trimestrale di Diritto e Procedura Civile 1978.

Montoro Ballesteros, Alberto, El deber jurídico, Cuadernos de Teoría Fundamental del Derecho, Universidad de Murcia, № 14, 1993.

Morón, Manuel, Derecho Procesal Civil (Cuestiones fundamentales), Marcial Pons, Madrid, 1993.

Ortells Ramos, Manuel, Derecho Procesal, Introducción (con Sánchez y Cámara), Edisofer Libros Jurídicos, Madrid, 2006.

Pacheco Guevara, Andrés, "Justicia gratuita y tutela judicial efectiva", Cuadernos de Derecho Judicial, Justicia gratuita, CGPJ, Madrid, 1995.

Palomo Vélez, Diego, "Proceso civil oral: ¿Qué modelo de juez requiere?", en De la Oliva Santos, Andrés; Palomo, Diego (Coords.), Proceso Civil. Hacia una nueva justicia civil, Editorial Jurídica de Chile, Santiago, 2007.

Pıcó I Junor, Joan, Las garantías constitucionales del proceso, Bosch Editor, Barcelona, 1997.

Ramos Méndez, Francisco, Derecho y proceso, Bosch Editor, Barcelona, 1979.

Rifá Soler, José; Richard González, Manuel; Riaño Brun, Iñaki, Derecho Procesal Civil, Vol. I, Gobierno de Navarro, Pamplona, 2005.

Rodríguez García, Nicolás, Justicia gratuita: un imperativo constitucional, Editorial Comares, Granada, 2000.

SerRano Hoyos, Gregorio, La prohibición de indefensión y su incidencia en el proceso, Editorial Comares, Granada, 1997. 
TARUfFo, Michele, "Idee per una teoria della decisione giusta". Sui Confini. Scritti sulla giustizia civile, II Mulino, Bolonia, 2002.

, "Investigación judicial y producción de prueba por las partes", Revista de Derecho de la Universidad Austral de Chile, Vol. XV, № 2, 2003.

, La prueba, Marcial Pons, Madrid, 2008.

TARZIA, Giuseppe, "Problemi del contradditorio nell istruzione probatoria civile", Rivista di Diritto Processuale No 3, 1984.

" "Poteri delle parti e poteri del giudice", en Problemi del processo civile di cognizione, Cedam, Padova, 1989.

Trocker, Nicolò, Processo civile e costituzione. Problemi di diritto tedesco e italiano, Giuffrè Editore, Milán, 1974.

UbertazzI, Giovanni, "Divieto di discriminazione e uguaglianza delle armi nel processo civile", Rivista Trimestrale di Diritto e Procedura Civile año XXXI, 1977.

UberTIS, Giulio, "Neutralità metodologica del giudice e principio di acquisizione processuale", Rivista Italiana di Diritto e Procedura Penal, No 50, 2007.

Vázquez Sotelo, José Luis, "Los principios del proceso civil", Revista Justicia No 93, 1993.

Verde, Giovanni, Profili del proceso civile. Parte generale, $2^{\text {a }}$ Edición, Jovene Editore, Nápoles, 1988. 
